\title{
PAFc, a Key Player in MLL-rearranged Leukemogenesis
}

\author{
Jiaying Tan, Andrew G. Muntean, Jay L. Hess \\ * Department of Pathology, University of Michigan Medical School, Ann Arbor MI, USA, 48109
}

Correspondence to: Jay L. Hess, e-mail: jayhess@umich.edu

Keywords: oncoprotein, leukemia, oncotarget, transcription

Received: September 8, 2010, Accepted: October 5, 2010,

Published: October 5, 2010

Copyright: ( ) Tan et al. This is an open-access article distributed under the terms of the Creative Commons Attribution License, which permits unrestricted use, distribution, and reproduction in any medium, provided the original author and source are credited.

\section{ABSTRACT:}

\begin{abstract}
Recent studies identified an interaction between the Polymerase Associated Factor complex (PAFC) and Mixed Lineage Leukemia (MLL), including MLLrearranged oncoproteins. This interaction is critical for MLL transcriptional activity and MLL-rearranged leukemogenesis. Here, we discuss the potential molecular role of the PAFc in transcriptional dysregulation of MLL target genes and the interplay between PAFc and MLL-rearranged oncoproteins in leukemogenesis.
\end{abstract}

\section{INTRODUCTION}

The mixed lineage leukemia gene $M L L$, the human homolog of the Drosophila trithorax gene, encodes a histone $\mathrm{H} 3$ lysine 4 (H3K4) methyltransferase that positively regulates multiple homeobox transcription factors, including Hoxa9 and MEISI, which are pivotal for leukemogenesis [1]. MLL rearrangements that generate MLL-rearranged oncoproteins are associated with a variety of acute lymphoid and myeloid leukemias that have a dismal prognosis [2]. To date, more than 50 different translocation fusion partners have been identified, among which the most common are nuclear proteins with transcriptional activating activity [2]. In acute lymphoblastic leukemias (ALL), the most common translocations are $\mathrm{t}(11 ; 19)$ and $\mathrm{t}(4 ; 11)$, resulting in the fusion proteins MLL-ENL and MLL-AF4, respectively. In contrast, the $\mathrm{t}(9 ; 11)$ translocation, resulting in the MLLAF9 fusion protein, is more frequently found in acute myeloid leukemias (AML). In addition to the nuclear translocation partners, another class of MLL fusion partners consists of cytoplasmic proteins that contain dimerization domains, such as AF6. Dimerization of these MLL fusion proteins leads to potent transcriptional activation and is essential for their leukemogenic capacity; however, the detailed leukemogenic mechanism remains elusive [3, 4]. $M L L$-related translocations are also commonly observed in secondary acute leukemias after topoisomerase inhibitor treatment [5]. In addition, around $8 \%$ of AML patients with normal cytogenetics harbor internal tandem duplications of partial MLL N-terminal sequence, known as $M L L-P T D$ (Fig. 1). Overall, genetic lesions in the $M L L$ gene are associated with more than
$80 \%$ infant leukemias and approximately $10 \%$ adult leukemias [2].

MLL is a ubiquitously expressed multi-domain protein required that has been shown to be essential for the survival of hematopoietic stem and progenitor cell populations [2]. Although multiple featured domains are present throughout the wild-type MLL protein, only the $\mathrm{N}$-terminus containing the Menin interaction domain, AT-hooks and CxxC-RD2 domain (up to the break point region) is invariably retained in all $M L L$-rearranged

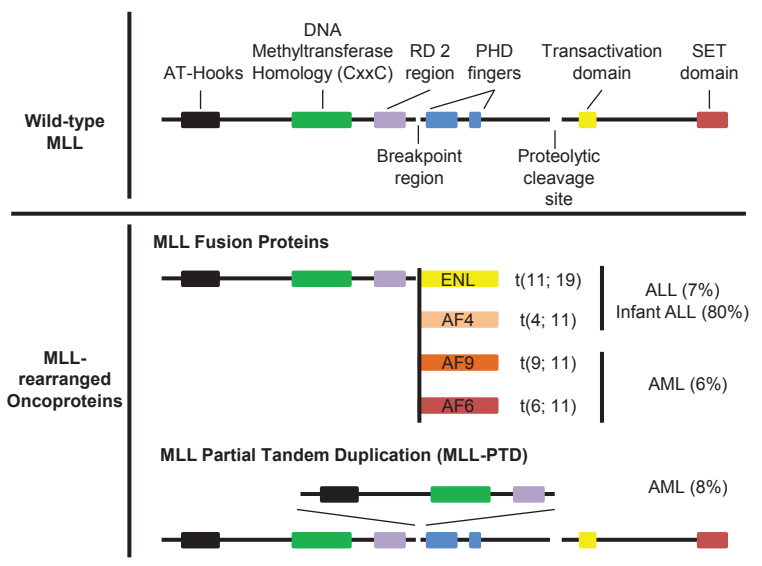

Figure 1: Schematic of wild-type MLL and MLLrearranged oncoproteins. Major functional domains and the proteolytic cleavage site of wild-type MLL are indicated. MLL fusion proteins consist of the N-terminus of wild-type MLL (up to the breakpoint region) fused in frame with a translocation partner (either a nuclear protein, such as ENL, AF4 and AF9, or a cytoplasmic protein, such as AF6). MLL-PTD is generated by exon duplication of the sequences encoding the N-terminus of wild-type MLL at the breakpoint region [32]. 
oncoproteins, whereas the Plant Homeodomain (PHD) and the SET domain, which is required for the histone methyltransferase activity, are consistently deleted (Fig. 1) [6]. Menin, a tumor suppressor encoded by the MEN1 gene, has been shown to directly interact with the extreme N-terminus of MLL, and this interaction is essential for MLL-rearranged leukemogenesis [6, 7]. A previous study has demonstrated that this interaction also involves a chromatin-associated protein, LEDGF (lens epithelium-derived growth factor) [8]. The $\mathrm{CxxC}$ domain selectively binds unmethylated CpG DNA sequence and aids in the localization of MLL fusion proteins to the target loci, protecting the corresponding regions against DNA methylation [9]. However, the role of the CxxC$\mathrm{RD} 2$ region, particularly the $\mathrm{RD} 2$ region immediately $\mathrm{N}$ terminal to the breakpoint region, in the cellular activities of wild-type MLL or MLL fusion proteins remains elusive. The importance of this region is highlighted by recent work by Bach et al. who clearly demonstrated that the DNA-binding affinity alone does not fully account for the indispensible role of this region in leukemogenesis, indicating the presence of uncharacterized activities/ interactions critical for MLL-rearranged leukemogenesis [10].

Our recent study, as well as the work from Milne et al., helps to clarify the role of the CxxC-RD2 region in MLL-rearranged leukemogenesis. Using mass spectrometry, we found that the Polymerase Associated Factor complex (PAFc) interacts with this region and that this interaction is critical for MLL transcriptional activity as well as leukemogenesis [11,12]. PAFc is a multi-protein complex, with the core components of PAF1, LEO1, CDC73, CTR9 and WDR61 [13-16]. Increasing evidence has revealed that PAFc plays important roles in a wide range of biological processes, including the initiation, elongation and termination of gene transcription, cell cycle regulation, mRNA processing, $\mathrm{H} 2 \mathrm{~B}$ monoubiquitination, H3K4 methylation and H3K79 methylation [17-19]. In addition, several components of PAFc are known to play important roles in cancer biology. For instance, PAF1 is shown to be upregulated or amplified in prostate cancer, whereas CDC73 has been associated with multiple types of human cancers, such as breast, renal and gastric cancer, as well as the hyperparathyroidism-jaw tumor syndrome $[16,17]$. Previous studies have demonstrated that the yeast PAF complex is required for the recruitment of the yeast Set1 methyltransferase complex, termed COMPASS, to RNA polymerase II; the interaction is also indispensible for both COMPASS mediated histone H3K4 and Dot1L mediated H3K79 methylation $[14,20]$. Given these results, it seemed to be likely that the MLL complex, the human homolog of COMPASS, is also physiologically and functionally associated with PAFc. Indeed, by mass spectrum analysis, we demonstrated that PAFc interacts with the CxxC-RD2 region of MLL, a region that is always retained in MLL-rearranged oncoproteins. Detailed mapping revealed two interaction sites flanking the $\mathrm{CxxC}$ domain with two individual components of PAFc. Most importantly, we were able to show that the PAFc-MLL interaction enhances the transcriptional activation by MLL-AF9 and plays an indispensible role in MLL-AF9 mediated transformation [11].

Characterization of the PAFc-MLL interaction provides valuable insight into the mechanisms of $M L L$ rearranged leukemogenesis. The best defined target genes of MLL are the clustered homeobox (Hox) genes, a transcription factor family important in cell fate determination during development. Among these targets, Hoxa9 and its cofactor Meis1 have been shown to be crucial for MLL-rearranged leukemogenesis. Normally, Hoxa9 and Meis 1 are only briefly expressed in hematopoietic stem cell and progenitor cell populations

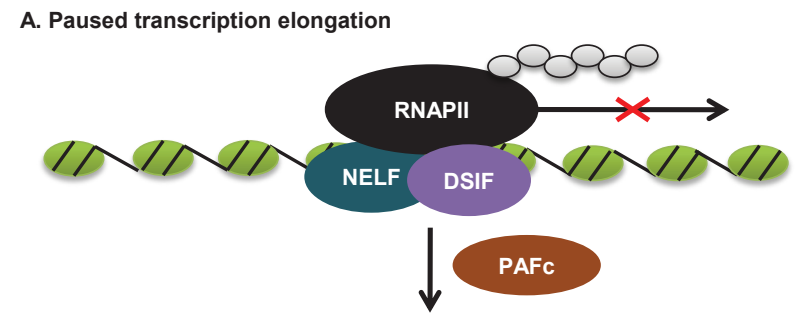

B. Transition to transcription elongation
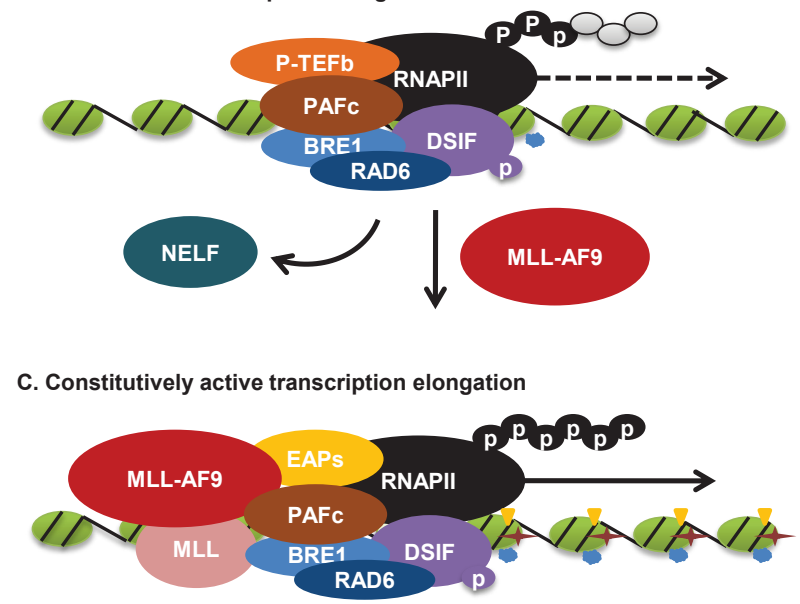

Figure 2: Schematic of a potential mechanism of MLLrearranged leukemogenesis. (A) In the absence of PAFc, RNA polymerase II (RNAPII) elongation is inhibited by the negative elongation factor (NELF) in collaboration with the DRB sensitivity-inducing factor DSIF. (B) DSIF recruits PAFc that directly interacts with the E1/E2 ubiquitin ligase complex BRE1/RAD6, resulting in histone H2B monoubiquitination. Recruitment of positive transcription elongation factor $b$ (P-TEFb) blocks the negative actions of NELF and DSIF by P-TEFb-dependent phosphorylation of RNAP II CTD and DSIF, priming the target promoter for transcription elongation (C) The interaction between PAFc and the most common MLLrearranged oncoproteins (represented by MLL-AF9) recruits the ENL-associated proteins (EAPs) that include multiple common MLL translocation partners, DOT1L and P-TEFb to the target loci, promoting H2B monoubiquitination ( ), H3K4 methylation $(+)$ and $\mathrm{H} 3 \mathrm{~K} 79$ methylation ( $)$, resulting in constitutively activated transcription. 
and are then rapidly down regulated during hematopoietic differentiation [21-23]. However, in the presence of MLLrearranged oncoproteins, both remain expressed at high levels, which accounts for their leukemogenic capacity. Although many interaction partners of MLL-rearranged proteins have been identified and shown to be important in leukemogenesis, it remains unclear what are the exact molecular mechanisms responsible for the dysregulation of the expression of these target genes.

Aside from our identification of the PAFc-MLL interaction, several lines of evidence also indicate the direct role of PAFc in Hox gene dysregulation in MLLrearranged leukemias. First, increasing evidence suggests that a significant mechanism for Hox gene expression is mediated through regulating transcriptional elongation [24], a process in which PAFc has been known to play a key regulatory role [16]. Second, we observed a significant dose-dependent transcriptional activation of the Hoxa9 promoter induced by MLL-AF9 overexpression, whereas wild-type MLL overexpression only delivered a somewhat more muted response, suggesting the differential roles of PAFc in cellular activities of MLLrearranged oncoproteins vs. wild-type MLL. Third, a previous study by Chen et al. has demonstrated that the susceptibility of hematopoietic progenitors to MLL-AF9induced transformation decreases along differentiation [25], consistent with the decreasing PAFc expression along hematopoietic differentiation shown by our work and others $[11,26]$. Based on these findings, a potential mechanism for MLL-rearranged leukemogenesis is that by interacting with PAFc, MLL-rearranged oncoproteins are able to stably engage the basic transcription elongation machinery at target loci, such as Hoxa9 and Meis 1, to constitutively activate transcription, leading to leukemogenesis. Therefore, PAFc may be a crucial component mediating the dysregulation of normal transcription elongation of MLL target genes by MLLrearranged oncoproteins (Fig. 2).

Under normal conditions, Hoxa9 is expressed in primitive hematopoietic cells, playing a significant role in early hematopoiesis [27, 28]. During hematopoietic differentiation, Hoxa9 expression is rapidly silenced, likely by pausing transcription elongation, an important mechanism regulating hox gene expression in Drosophila $[24,29]$. In this case, although RNA polymerase II (RNAP II) still localizes at the promoter region, its C-terminal domain (CTD) is unphosphorylated, and transcription elongation is inhibited by the negative elongation factor (NELF) in collaboration with the DRB sensitivity-inducing factor (DSIF) (Fig. 2A). DSIF recruits PAFc that directly interacts with the E1/E2 ubiquitin ligase complex BRE1/ RAD6, resulting in histone $\mathrm{H} 2 \mathrm{~B}$ monoubiquitination. Meanwhile, the recruitment of positive transcription elongation factor $\mathrm{b}(\mathrm{P}-\mathrm{TEFb})$ reverts the negative actions of NELF and DSIF by P-TEFb-dependent phosphorylation of RNAP II CTD and DSIF [16]. Thus, in the presence of PAFc, the target gene promoter region can progress to the active elongation stage (Fig. 2B). It is worth noting that this status is probably a temporary transition stage, dynamically regulated by cell-specific mechanisms, such as the abundance of PAFc, the binding affinity of other transcription elongation machinery components determined by the phosphorylation level of RNAP II CTD, the recruitment of histone methyltransferases, such as wild-type MLL and DOT1L, exerting H3K4 and H3K79 methylation, respectively, and the regulation of their enzymatic activities. For instance, in hematopoietic stem cells and early-stage progenitor cells, PAFc is expressed at a high level; therefore, this temporary transition status is more likely to progress into a fully active elongation stage, which in turn leads to the Hox gene expression. In contrast, in the differentiated cells, PAFc downregulation may revert this transition status back to the inactive transcription stage, silencing the Hox gene expression. The dynamics of the multiple regulatory mechanisms is likely to be disrupted by MLL-rearranged oncoproteins, such as MLL-AF9.

The most common MLL-rearranged oncoproteins, including MLL-AF9, MLL-ENL and MLL-AF4, are known to interact with a protein complex termed ENLassociated proteins (EAP) or a closely related complex called AEP for AF4 family/ENL family/P-TEFb complex [11]. By interacting with PAFc, these MLL-rearranged oncoproteins recruits EAP that includes DOT1L, P-TEFb and multiple common MLL translocation partners to the target loci, promoting H3K79 methylation, resulting in dysregulated constitutively active gene expression (Fig. 2C). In addition, wild-type MLL has recently been shown to synergize with MLL-AF9, which furthering increases the $\mathrm{H} 3 \mathrm{~K} 4$ methylation level, and presumably contributing to target gene transcription [30]. Notably, in the study by Chen et al., the authors showed that LSK $\left(\mathrm{Lin}_{-} \mathrm{Sca}{ }^{+} \mathrm{C}-\mathrm{kit}^{+}\right)$stem cells, but not the more differentiated committed granulocyte-monocyte progenitors (GMPs), can be transformed by MLLAF9 under endogenous regulatory control, suggesting that under physiological conditions, additional linagespecific transcription factor(s) or coactivators(s), other than the MLL-rearranged oncoproteins are critical for leukemogenesis [25]. Given the downregulation of PAFc during hematopoietic differentiation, it is possible that PAFc at least partially accounts for the susceptibility of different progenitor populations to MLL fusion protein induced leukemogenesis.

A number of questions remain regarding the mechanism of the PAFc-MLL interaction in MLLrearranged leukemogenesis. First, apart from the most common $M L L$ translocations resulting in MLL fusion proteins with a nuclear translocation partner, MLL fusion proteins with cytoplasmic partners and MLL-PTD have not been extensively studied. Therefore, the leukemogenic mechanisms of MLL-PTD and MLL-rearranged 
oncoproteins with a cytoplasmic partner, both of which in effect involve duplication of the N-terminus of MLL (up to the breakpoint region) by either intramolecular partial tandem duplication or intermolecular dimerization, are unknown [31]. Given the pivotal role of PAFc in MLL-rearranged leukemogenesis, it will be important to determine if either of these two types of MLL-rearranged oncoproteins involves enhanced physical or functional interaction with PAFc. Second, it is still unclear how, and to what extent, PAFc plays differential roles in the cellular activities of MLL-rearranged oncoproteins vs. wild-type MLL. It will be important to determine if such a therapeutic window exists for targeting PAFc, for example, through targeting MLL-PAFc interaction with small molecule inhibitors, which could be used as a new therapy for MLL-rearranged leukemias.

\section{CONFLICT OF INTEREST STATEMENT}

The authors declared no potential conflicts of interest.

\section{ACKNOWLEDGEMENTS}

A.G.M. is supported by a postdoctoral training grant from the National Institutes of Health (T32 HL07622). J.L.H. is supported by the National Institutes of Health (CA92251) and by a SCOR grant from the Leukemia and Lymphoma Society. We apologize to those whose contributions were not cited due to space limitations.

\section{REFERENCES}

1. Hess JL. Mechanisms of transformation by MLL. Crit Rev Eukaryot Gene Expr 2004;14(4):235-54.

2. Krivtsov AV, Armstrong SA. MLL translocations, histone modifications and leukaemia stem-cell development. Nat Rev Cancer 2007;7(11):823-33.

3. Martin ME, Milne TA, Bloyer S, Galoian K, Shen W, Gibbs D, Brock HW, Slany R, Hess JL. Dimerization of MLL fusion proteins immortalizes hematopoietic cells. Cancer Cell 2003;4(3):197-207.

4. So CW, Lin M, Ayton PM, Chen EH, Cleary ML. Dimerization contributes to oncogenic activation of MLL chimeras in acute leukemias. Cancer Cell 2003;4(2):99110.

5. Felix CA. Secondary leukemias induced by topoisomerasetargeted drugs. Biochim Biophys Acta 1998;1400(13):233-55

6. Caslini C, Yang Z, El-Osta M, Milne TA, Slany RK, Hess JL. Interaction of MLL amino terminal sequences with menin is required for transformation. Cancer Res 2007;67(15):7275-83.

7. Chen YX, Yan J, Keeshan K, Tubbs AT, Wang H, Silva A, Brown EJ, Hess JL, Pear WS, Hua X. The tumor suppressor menin regulates hematopoiesis and myeloid transformation by influencing Hox gene expression. Proc Natl Acad Sci U S A 2006;103(4):1018-23.

8. Yokoyama A, Cleary ML. Menin critically links MLL proteins with LEDGF on cancer-associated target genes. Cancer Cell 2008;14(1):36-46.

9. Ayton PM, Chen EH, Cleary ML. Binding to nonmethylated CpG DNA is essential for target recognition, transactivation, and myeloid transformation by an MLL oncoprotein. Mol Cell Biol 2004;24(23):10470-8.

10. Bach C, Mueller D, Buhl S, Garcia-Cuellar MP, Slany $\mathrm{RK}$. Alterations of the $\mathrm{CxxC}$ domain preclude oncogenic activation of mixed-lineage leukemia 2. Oncogene 2009;28(6):815-23.

11. Muntean AG, Tan J, Sitwala K, Huang Y, Bronstein J, Connelly JA, Basrur V, Elenitoba-Johnson KS, Hess JL. The PAF complex synergizes with MLL fusion proteins at HOX loci to promote leukemogenesis. Cancer Cell 2010;17(6):609-21.

12. Milne TA, Kim J, Wang GG, Stadler SC, Basrur V, Whitcomb SJ, Wang Z, Ruthenburg AJ, Elenitoba-Johnson $\mathrm{KS}$, Roeder RG, Allis CD. Multiple interactions recruit MLL1 and MLL1 fusion proteins to the HOXA9 locus in leukemogenesis. Mol Cell 2010;38(6):853-63.

13. Kim J, Guermah M, Roeder RG. The Human PAF1 Complex Acts in Chromatin Transcription Elongation Both Independently and Cooperatively with SII/TFIIS. Cell 2010;140(4):491-503.

14. Rozenblatt-Rosen O, Hughes CM, Nannepaga SJ, Shanmugam KS, Copeland TD, Guszczynski T, Resau $\mathrm{JH}$, Meyerson M. The parafibromin tumor suppressor protein is part of a human Pafl complex. Mol Cell Biol 2005;25(2):612-20.

15. Zhu B, Mandal SS, Pham AD, Zheng Y, Erdjument-Bromage H, Batra SK, Tempst P, Reinberg D. The human PAF complex coordinates transcription with events downstream of RNA synthesis. Genes Dev 2005;19(14):1668-73.

16. Jaehning JA. The Pafl complex: Platform or player in RNA polymerase II transcription? Bba-Gene Regul Mech 2010;1799(5-6):379-88.

17. Chaudhary K, Deb S, Moniaux N, Ponnusamy MP, Batra SK. Human RNA polymerase II-associated factor complex: dysregulation in cancer. Oncogene 2007;26(54):7499-507.

18. Kim J, Roeder RG. Direct Bre1-Paf1 complex interactions and RING finger-independent Bre1-Rad6 interactions mediate histone $\mathrm{H} 2 \mathrm{~B}$ ubiquitylation in yeast. J Biol Chem 2009;284(31):20582-92.

19. Kim J, Guermah M, McGinty RK, Lee JS, Tang Z, Milne TA, Shilatifard A, Muir TW, Roeder RG. RAD6Mediated transcription-coupled H2B ubiquitylation directly stimulates H3K4 methylation in human cells. Cell 2009;137(3):459-71.

20. Krogan NJ, Dover J, Wood A, Schneider J, Heidt J, Boateng MA, Dean K, Ryan OW, Golshani A, Johnston M, 
Greenblatt JF, Shilatifard A. The Pafl complex is required for histone $\mathrm{H} 3$ methylation by COMPASS and Dot1p: linking transcriptional elongation to histone methylation. Mol Cell 2003;11(3):721-9.

21. Zeisig BB, Milne T, Garcia-Cuellar MP, Schreiner S, Martin ME, Fuchs U, Borkhardt A, Chanda SK, Walker J, Soden R, Hess JL, Slany RK. Hoxa9 and Meis1 are key targets for MLL-ENL-mediated cellular immortalization. Mol Cell Biol 2004;24(2):617-28.

22. Lawrence HJ, Sauvageau G, Humphries RK, Largman C. The role of HOX homeobox genes in normal and leukemic hematopoiesis. Stem Cells 1996;14(3):281-91.

23. Magli MC, Largman C, Lawrence HJ. Effects of HOX homeobox genes in blood cell differentiation. J Cell Physiol 1997;173(2):168-77.

24. Chopra VS, Hong JW, Levine M. Regulation of Hox gene activity by transcriptional elongation in Drosophila. Curr Biol 2009;19(8):688-93.

25. Chen W, Kumar AR, Hudson WA, Li Q, Wu B, Staggs RA, Lund EA, Sam TN, Kersey JH. Malignant transformation initiated by Mll-AF9: gene dosage and critical target cells. Cancer Cell 2008;13(5):432-40.

26. Ding L, Paszkowski-Rogacz M, Nitzsche A, Slabicki MM, Heninger AK, de Vries I, Kittler R, Junqueira M, Shevchenko A, Schulz H, Hubner N, Doss MX, Sachinidis A, Hescheler J, Iacone R, Anastassiadis K, Stewart AF, Pisabarro MT, Caldarelli A, Poser I, Theis M, Buchholz F. A genome-scale RNAi screen for Oct4 modulators defines a role of the Pafl complex for embryonic stem cell identity. Cell Stem Cell 2009;4(5):403-15.

27. Pineault N, Helgason CD, Lawrence HJ, Humphries RK. Differential expression of Hox, Meis1, and Pbx1 genes in primitive cells throughout murine hematopoietic ontogeny. Exp Hematol 2002;30(1):49-57.

28. Lawrence HJ, Christensen J, Fong S, Hu YL, Weissman I, Sauvageau G, Humphries RK, Largman C. Loss of expression of the Hoxa-9 homeobox gene impairs the proliferation and repopulating ability of hematopoietic stem cells. Blood 2005;106(12):3988-94.

29. Brookes E, Pombo A. Modifications of RNA polymerase II are pivotal in regulating gene expression states. EMBO Rep 2009;10(11):1213-9.

30. Thiel AT, Blessington P, Zou T, Feather D, Wu X, Yan J, Zhang H, Liu Z, Ernst P, Koretzky GA, Hua X. MLL-AF9induced leukemogenesis requires coexpression of the wildtype Mll allele. Cancer Cell 2010;17(2):148-59.

31. Dou Y, Hess JL. Mechanisms of transcriptional regulation by MLL and its disruption in acute leukemia. Int J Hematol 2008;87(1):10-8.

32. Strout MP, Marcucci G, Bloomfield CD, Caligiuri MA. The partial tandem duplication of ALL1 (MLL) is consistently generated by Alu-mediated homologous recombination in acute myeloid leukemia. Proc Natl Acad Sci U S A 1998;95(5):2390-5. 